DOI 10.37882/2500-3682.2021.09.12

\title{
СВЯЗЬ КОНКОРДАНТНЫХ ЦЕЛЕЙ И СУБЪЕКТИВНОГО БЛАГОПОЛУЧИЯ В ПЕРИОД РАННЕЙ ВЗРОСЛОСТИ
}

\section{THE RELATIONSHIP BETWEEN CONCORDANT GOALS AND SUBJECTIVE WELL-BEING IN EARLY ADULTHOOD

\author{
E. Potapova \\ K. Kalinovskaya \\ A. Moiseenko \\ V. Kembel
}

Summary: The article presents the results of a study that analyzes the relationship of concordant goals (corresponding to the deep self), and the achievement of which is accompanied by an increase in psychological well-being and other positive effects. The study was conducted among respondents in the period of early adulthood, one of the main tasks of which is to rethink the life path and expand the life perspective, based on the implementation of their own life plan. The practical significance of this research consists in a combination of coaching and psychological support with an in-depth study of personal needs for the most satisfactory life planning.

Keywords: concordance of goals, subjective well-being, causal orientation, early adulthood.
Потапова Екатерина Вадимовна

К.nсх.н., дочент, Сибирский федеральный университет, Красноярск

potapowa.catia2011@yandex.ru

Калиновская Ксения Сергеевна

К.nсх.н., доцент, Сибирский федеральный университет, Красноярск

kartashovaks@mail.ru

Моисеенко Анна Николаевна

профессиональный коуч, Международный Эриксоновский университет коучинга по стандартам Международной

Федерации коучинга (ICF)

partaveitsister@gmail.com

Кембель Вера Радионовна

К.nсх.н., дочент, Красноярский Государственный Медицинский Университет vera_kembel@mail.ru

Аннотация: В статье представлены результаты исследования, в котором анализируется связь конкордантных целей (соответствующими глубинному Я), и достижение которых сопровождается ростом психологического благополучия и другими позитивными эффектами. Исследование проводилось среди респондентов, в период ранней взрослости, одной из основных задач которого является переосмысление жизненного пути и расширение жизненной перспективы, на основе реализации собственного жизненного замысла. Практическая значимость данного исследования, состоит в сочетании коучингового и психологического сопровождения с углубленным исследованием личностных потребностей для наиболее удовлетворительного жизненного планирования.

Ключевые слова: конкордантность целей, субъективное благополучие, каузальная ориентация, ранняя взрослость.

как личностно детерминированного процесса. Современная теория, поставившая во главу угла способность автономного осуществления выбора целей, была разработана американскими психологами Эдвардом Деси и Ричардом Райаном [10; 11; 12]. Теория самодетерминации (Self- Determination Theory - SDT) признана и популярна на Западе как современный подход к мотивации и регуляции действия. В отечественной науке развивается интерес к данной теории как к основе исследований связи личностной автономии и благополучия $[1 ; 3 ; 7]$.

В контексте данного подхода самодетерминация, или автономия, рассматривается как ощущение и реализация свободы выбора человеком способа поведения и существования в мире независимо от влияющих на него сил внешнего окружения и внутриличностных процессов. 
В СДТ виды целей различаются с точки зрения источников их порождения:

1. Ц Цели внутренней мотивации. Не обязательно приносят удовольствие.

2. Цели, заданные извне. Могут быть интернализированы.

К повышению субъективного благополучия приводит достижение внутренних целей, достижение заданных извне целей, даже очень успешное, лишь в малой степени отражается на ощущении счастья и благополучия.

Самой молодой теорий из данного кластера является теория содержания целей (Goal Contents Theory, GCT). K. Шелдоном была разработана модель конкордантности целей, которая обосновывается им, исходя из положений о трех базовых психологических потребностях. Как показал Шелдон, мера осознанности личной цели играет критическую роль в процессе ее постановки, способствуя выбору наиболее благоприятной для человека цели. Коонкордатные цели исходят из «ядра» личности, они связаны с базовой мотивацией, их достижение сопровождается ростом психологического благополучия и другими позитивными эффектами; это естественный механизм развития личности[9].

В данном исследовании мы работали с респондентами возрастом от 20 до 40 лет, что, согласно классификации американского психолога Г. Крайга, относится к периоду ранней взрослости. Данный возрастной период включает в себя кризис 30 лет или кризис эмансипации, проявляющийся в виде ощущения монотонности, заданности, предопределенности, также кризис может быть связан с переосмыслением жизненного пути. Выход из кризиса - в расширении жизненной перспективы, в переоценке ценностей, в серьезном изменении протекания психических процессов и межличностных коммуникаций. Успешное прохождение данного возрастного периода влияет на уровень субъективного благополучия [5].

По мнению Шамионова Р.М., психологическое благополучие - это отношение человека к себе, к своей жизни, к жизненным процессам, значимым для человека с точки зрения усвоенных нормативных представлений о внешней и внутренней среде, которое определяется чувством удовлетворённости [8].

Каузальная ориентация - тип мотивационной подсистемы в сочетании с соответствующими когнитивными, аффективными и другими психологическими характеристиками [4]. Существует три типа каузальных ориентаций - внутренний, внешний и безличный. Каждый из трех типов присутствует в системе мотивации человека, но лишь один из них преобладает и является ведущим.
Автономный тип определяет ориентацию на внутреннюю мотивационную подсистему, или «самодетерминацию». Базовые потребности находятся на высоком уровне осознанности и всегда учитываются. Характерна высокая гибкость поведения и особая чувствительность к переменам в среде. Отмечается способность преобразовывать автоматические действия в автономно регулируемые.

Эмпирическое исследование влияния конкордантных целей на уровень субъективного благополучия проводилось в Красноярске в период 2020-2021 годов. Была сформирована группа респондентов из числа обратившихся к психологу с запросом на работу с целеполаганием. Количество респондентов - 12 человек, в возрасте от 25 до 37 лет.

Объект исследования: конкордантные цели, субъективное благополучие.

Предмет исследования: связь конкордантных целей и субъективного благополучия

Нами была выдвинута гипотеза о том, что при работе с целями, направленной на осознание конкордантных целей, повышается уровень субъективного благополучия и внутренней каузальной ориентации, а уровень внешней и безличной каузальной ориентации будут снижаться.

\section{Анализ и интерпреташия полученных $\Delta$ анных исслеАования}

На первом этапе была проведена первичная диагностика респондентов по методикам в качестве отправной точки для сравнения. Были получены следующие результаты. По опроснику Индекс жизненной удовлетворенности выявлены средние показатели (табл. 1):

Таблица 1.

Результаты опросника

«Индекс жизненной удовлетворенности»

\begin{tabular}{|l|c|}
\multicolumn{1}{c|}{ Наименование шкалы } & Средний показатель \\
\hline Индекс жизненной удовлетворенности & 28,2 \\
\hline Интерес к жизни & 6 \\
\hline Последовательность в достижении целей & 5,9 \\
\hline Согласованность целей & 4,6 \\
\hline Положительная оценка себя & 6 \\
\hline Общий фон настроения & 5,5 \\
\hline
\end{tabular}

На первом этапе диагностика с помощью русскоязычного опросника каузальных ориентаций показала, что у всех респондентов преобладающей является внутренняя каузальная ориентация, при этом соотношение с другими видами каузальной ориентации различается. 
Согласно теории самодертминации, у каждого человека присутствуют все три вида каузальной ориентации, но тип преобладающей мотивации будет определять индивидуальную мотивационную подсистему. Средний показатель внутренней каузальной ориентации составил 146 , внешней - 88, безличной - 83.

Показатели субъективного благополучия на первом этапе исследования выражены в следующих средних значениях (табл. 2):

Показатели субъективного благополучия

Таблица 2. на первом этапе

\begin{tabular}{|l|c|}
\multicolumn{1}{|c|}{ Наименование шкалы } & Среднее \\
\hline Психологическое благополучие & 348 \\
\hline Позитивные отношения & 51 \\
\hline Автономия & 57 \\
\hline Управление средой & 53 \\
\hline Личностный рост & 68 \\
\hline Цель в жизни & 60 \\
\hline Самопринятие & 57 \\
\hline Баланс аффекта & 111 \\
\hline Осмысленность жизни & 95 \\
\hline Человек как открытая система & 63 \\
\hline
\end{tabular}

Полученные данные послужили отправной точкой для дальнейшей работы и оценки эффективности той работы с целями, которая была проведена с респондентами на этапах 2 и 3.

Этап 2. Проведение психологического сопровождения с использованием методики формулирования целей (SMART) и методики коучинговых вопросов Д. Клаттербэка.

Была организована групповая встреча с участниками исследования на тему формулировки цели. Встреча состояла из следующих этапов:

1. Лекционная часть. Знакомство с методикой формулировки цели SMART. Расшифровка и комментарий к каждому параметру формулировки. Цель должна быть сформулирована по следующим параметрам: конкретная, измеримая, достижимая, актуальная, с четкими сроками.

2. Самостоятельная работа участников встречи по формулировке собственной цели с использованием методики SMART.

3. Обсуждение с участниками выполненной методики. Ответы на вопросы, комментарии. Сопровождение участников при помощи методики коучинговых вопросов Д. Клаттербэка.

4. Повторная диагностика.
Результаты повторной диагностики выявили повышение по следующим показателям. В таблице собраны шкалы, по которым произошло повышение и процент участников, у которых это повышение произошло (табл. 3):

Таблица 3.

Результаты диагностики на втором этапе

\begin{tabular}{|l|c|}
\multicolumn{1}{c|}{ Показатель } & $\%$ \\
\hline Индекс жизненной удовлетворенности & 50 \\
\hline Последовательность в достижении целей & 50 \\
\hline Субъективное благополучие & 83 \\
\hline Управление средой & 75 \\
\hline Осмысленность жизни & 83 \\
\hline Внутренняя каузальная ориентация & 75 \\
\hline Внешняя каузальная ориентация & 58 \\
\hline
\end{tabular}

Из данной таблицы видно, что после проведения методики формулирования цели SMART у наибольшего количества участников исследования увеличились показатели по шкалам «позитивные отношения», «управление средой», «осмысленность жизни» и «психологическое благополучие». Также отмечено повышение по показателю «индекс жизненной удовлетворенности». Эти результаты не подтверждают наше первоначальное предположение о том, что работа с целями по формальным показателям не даст значимого повышения субъективного благополучия. Можно предположить, что структурирование и формулировка цели помогает конкретизировать цель, увидеть ее более ясно - это подтверждают и комментарии участниц исследования: «noявилось больще конкретики», "расписала чель на более мелкие шаги», "прояснилось понимание, чего именно я хочу достичь».

Оценивая по десятибалльной шкале пользу от выполнения данной методики, 33\% респондентов поставили 10 из 10, средняя оценка пользы от выполнения данной методики - 7 баллов из 10.

После проведения методики формулирования целей SMART участники отметили следующие эмоциональные состояния: интерес, уверенность, «силу», «что все могу». При этом некоторые участники отметили возникшее сопротивление и нежелание отвечать на некоторые вопросы по методике, которые показались «неудобными». Также несколько участников отметили, что упустили некоторые элементы методики - например, в блоке о ресурсах учли только временные ресурсы и не учли свои физические и психологические ресурсы для достижения цели.

Важно, что вырос показатель внешней каузальной ориентации. Можем предположить, что это связано с 
четко заданными извне параметрами по формулированию цели.

В следующей гистограмме можем видеть рост среднего показателя по шкалам индекса жизненной удовлетворенности относительно первого этапа исследования (рис. 1):

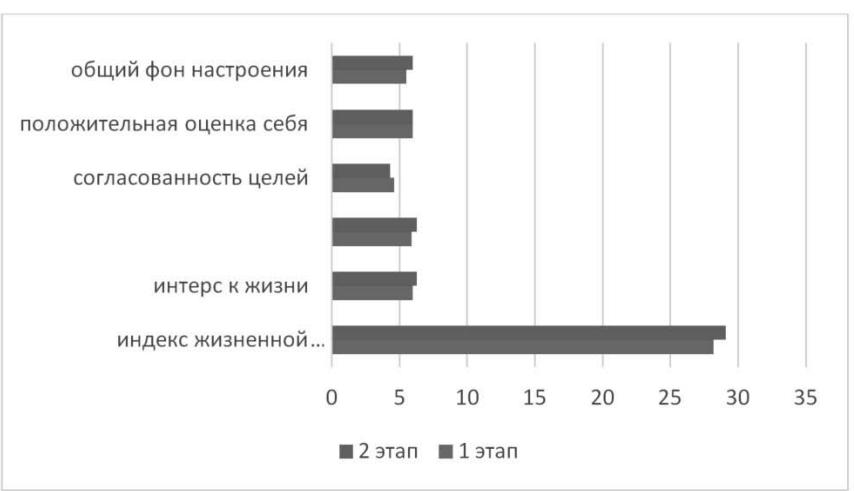

Рис. 1. Индекс жизненной удовлетворенности

По методике Шкала субъективного благополучия произошли следующие изменения средних показателей (рис. 2):

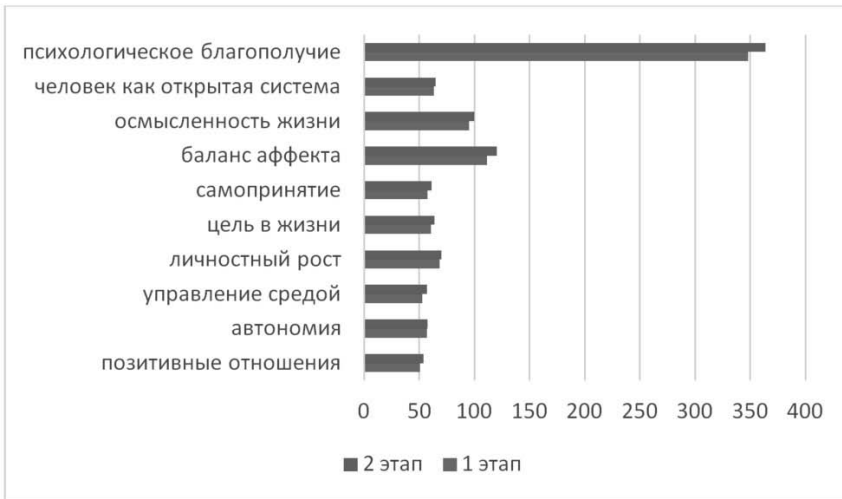

Рис. 2. Шкала психологического благополучия

Методика Русскоязычный опросник каузальных ориентаций показала следующие изменения в каузальных ориентациях участников исследования после проведения методики формулировки цели SMART (рис. 3):

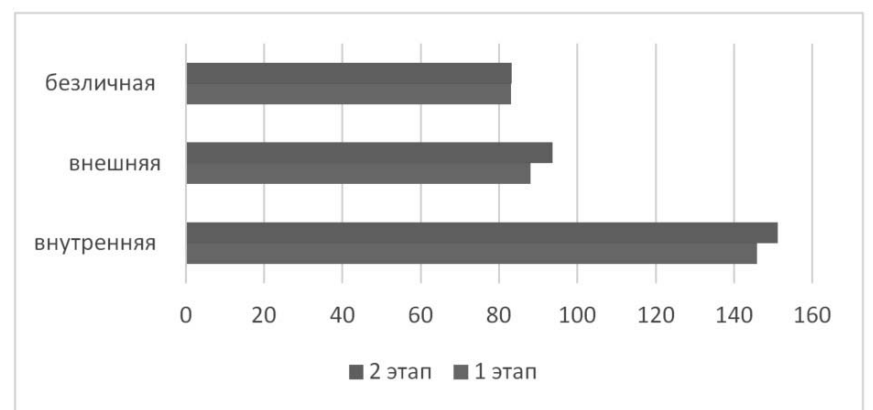

Рис. 3. Казуальные ориентации
Таким образом, по итогам проведения второго этапа эмпирического исследования можем сделать следующие выводы. Работа с целями с применением методики SMART, дополненная коучинговыми вопросами, позволила повысить показатели удовлетворенности и субъективного благополучия у респондентов.

Этап 3. Проведение методики М.Казанцева «Жизненный сценарий на линии времени» для осознания конкордантных целей.

На третьем этапе была организована групповая встреча с участниками исследования на тему работы с целями. Встреча состояла из следующих этапов:

1. Лекционная часть. Знакомство с методикой «Жизненный сценарий на линии времени».

2. Самостоятельная работа участников встречи по методике «Жизненный сценарий на линии времени».

3. Обсуждение с участниками выполненной методики. Ответы на вопросы, комментарии. Сопровождение участников при помощи методики коучинговых вопросов Д. Клаттербэка.

4. Повторная диагностика.

После проведения с респондентами методики М. Казанцева «Жизненный сценарий на линии времени» произошло повышение по следующим показателям (табл. 4):

Таблица 4.

Результаты диагностики на третьем этапе

\begin{tabular}{|l|c|}
\multicolumn{1}{|c|}{ Показатель } & $\%$ \\
\hline Индекс жизненной удовлетворенности & 66 \\
\hline Субъективное благополучие & 83 \\
\hline Цель в жизни & 66 \\
\hline Управление средой & 80 \\
\hline Осмысленность жизни & 66 \\
\hline Внутренняя каузальная ориентация & 58 \\
\hline
\end{tabular}

После работы по методике «Жизненный сценарий на линии времени» у наибольшего количества участников исследования увеличились показатели по шкалам «управление средой», «цель в жизни», «баланс аффекта», «осмысленность жизни», «человек как открытая система» и «психологическое благополучие». И понижение по шкалам внешней и безличной каузальной ориентации.

Оценивая по десятибалльной шкале пользу от выполнения данной методики, 50\% респондентов поставили 10 из 10, средняя оценка пользы от выполнения данной методики - 8 баллов из 10.

Значимым показателем эффективности данной работы также можно считать то, что 90\% респондентов нача- 
ли осуществлять действия по движению к своей цели на момент итогового анкетирования.

В следующей гистограмме можем видеть рост среднего показателя по шкалам индекса жизненной удовлетворенности относительно первого этапа и второго этапов исследования (рис. 4):

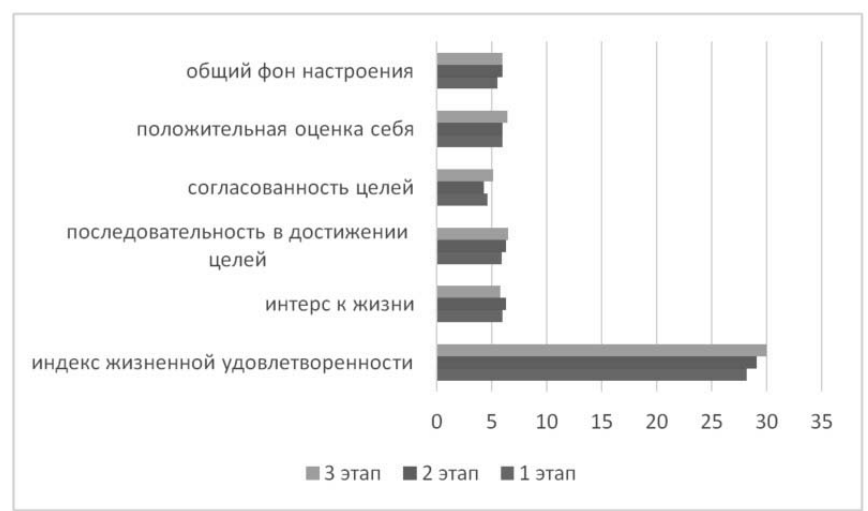

Рис. 4. Индекс жизненной удовлетворенности 2

В представленной выше гистограмме видно, что общий показатель Индекса жизненной удовлетворенности вырос и после второго, и после третьего этапа работы. Таким же образом выросли показатели по отдельным шкалам: положительная оценка себя, согласованность целей и последовательность в достижении целей. Можем предположить, что рост данных показателец связан с осуществленным спровождением в работе с целями, которое было направлено на осознание собственных конкордантных целей.

По методике Шкала субъективного благополучия произошли следующие изменения средних показателей (рис. 5):

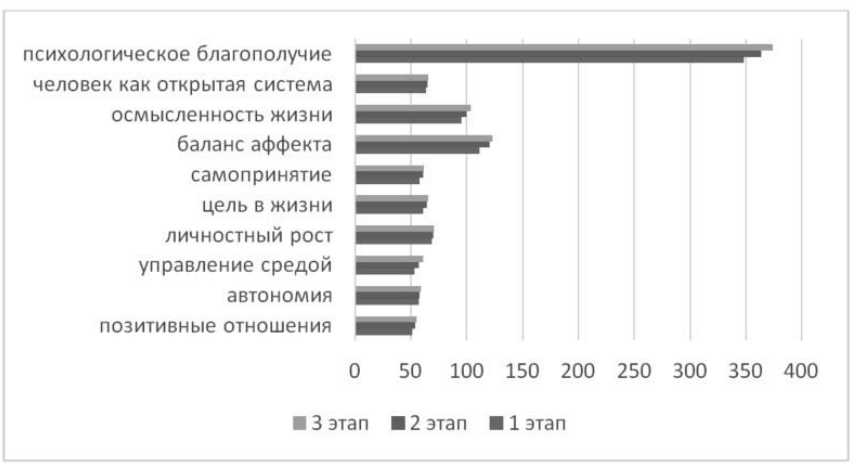

Рис. 5. Шкала субъективного благополучия 2

В представленной выше гистограмме видно, что общий показатель Субъективного благополучия вырос и после второго, и после третьего этапа работы. Таким же образом выросли показатели по всем остальным шкалам, в наибольшей мере рост произошел по шкалам: цель в жизни, управление средой, осмысленность жиз- ни. Можем предположить, что рост данных показателец связан с осуществленным спровождением в работе с целями, которое было направлено на осознание собственных конкордантных целей.

Методика «Русскоязычный опросник каузальных ориентаций» показала следующие изменения в каузальных ориентациях участников исследования после проведения методики формулировки цели SMART (рис. 6):

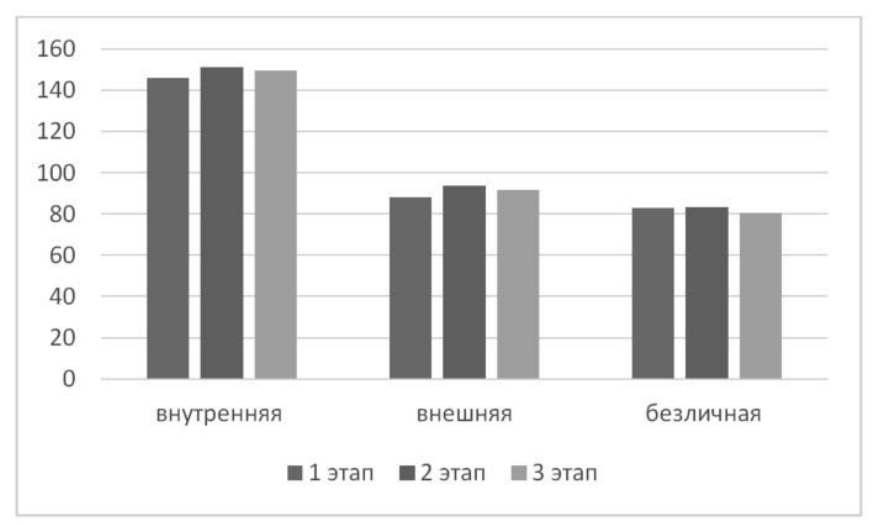

Рис. 6. Казуальные ориентации 2

Показатели внутренней каузальной ориентации выросли, а внешней и безличной стали меньше, как мы и предполагали. Можем предположить, что рост данных показателец связан с осуществленным спровождением в работе с целями, которое было направлено на осознание собственных конкордантных целей.

Данные результаты были статистически поттверждены с использование критерий $\chi^{2}$ Пирсона. Наше предположение можно считать достоверным: различия между полученными показателями субъективного благополучия и теоретическим распределением статистически значимы.

\section{Выводы}

Предположения, выдвинутые в начале исследования, частично подтвердились. Так, подтвердилась гипотеза о том, что при работе с целями, направленной на осознание конкордантных целей, повышается уровень субъективного благополучия и внутренней каузальной ориентации, а уровень внешней и безличной каузальной ориентации будут снижаться. Полученные данные были обработаны и доказана их статистическая достоверность.

Целью нашего исследования было выявить влияние конкордантных целей на уровень субъективного благополучия.

На основании полученных статистически достоверных данных можно сделать вывод, что работа с целями, 
направленная на осознание конкордантных целей, повышает уровень субъективного благополучия и жизнен- ной удовлетворенности, а также уровень внутренней каузальной ориентации.

\section{ЛИТЕРАТУРА}

1. Гордеева Т.0. Психология мотивации достижения. Москва: Смысл, 2006. 336 с.

2. Гордеева Т.0. Теория самодетерминации: настоящее и будущее. Часть 1: Проблемы развития теории // Психологические исследования: электронный научный журнал. 2010. № 4 (12). URL: http://psystudy.ru/index.php/num/2010n4-12/343-gordeeva12 (дата обращения: 05.08.2021)

3. Дергачева 0.Е. Теория самодетерминации // Большой психологический словарь / Сост. и общ. ред. Б.Г. Мещеряков, В.П. Зинченко. СПб., 2003. С. 483 484.

4. Дергачева 0.Е., Дорфман Л.Е., Леонтьев Д.А. Русскоязычная адаптация опросника каузальных ориентаций // Вестник Московского университета. Серия 14. Психология. 2008. №3. С. 91 - 106.

5. Крайг Г., Бокум Д. Психология развития. Москва: Питер. 2012.939 с.

6. Костенкова 0.М. Коучинг, его зарождение, развитие и внедрение // Современные научные исследования и инновации. 2018. № 2. URL: https://web. snauka.ru/issues/2018/02/85953 (дата обращения: 06.08.2021)

7. Леонтьев Д.А. Психология свободы: к постановке проблемы самодетерминации личности // Психологический журнал. 2000. С. 15-25.

8. Шамионов Р.М., Бескова Т.В. Методика диагностики субъективного благополучия личности // Психологические исследования. 2018. Т. 11, № 60. С. 8. URL: http://psystudy.ru/index.php/num/2018v11n60/1602-shamionov60.html (дата обращения: 06.08.2021)

9. Шелдон К. Введение в теорию самодетерминации и новые подходы к мотивации роста // Сибирский психологический журнал. 2016. № 62. С. 7-11.

10. Deci E.L. Intrinsic motivation. New York, NY: Plenum, 1975. 324 p.

11. Deci E.L., Ryan R.M. The general causality orientations scale: Self-determination in personality. Journal of Research in Personality, 1985. № 19(2). P. 109-134.

12. Deci E.L., Ryan R.M. The «what» and «why» of goal pursuits: Human needs and the self-determination of behavior. Psychological Inquiry, 2000. № 11(4). P. 227-268.

13. Kasser, T., \& Ryan, R.M. Further examining the American dream: Differential correlates of intrinsic and extrinsic goals. Personality and Social Psychology Bulletin, 1996. № 22(3). P. 280-287. URL: https://doi.org/10.1177/0146167296223006 (дата обращения: 04.08.2021)

○ Потапова Екатерина Вадимовна (potapowa.catia2011@yandex.ru), Калиновская Ксения Сергеевна (kartashovaks@mail.ru), Моисеенко Анна Николаевна (partaveitsister@gmail.com), Кембель Вера Радионовна (vera_kembel@mail.ru). Журнал «Современная наука: актуальные проблемы теории и практики»

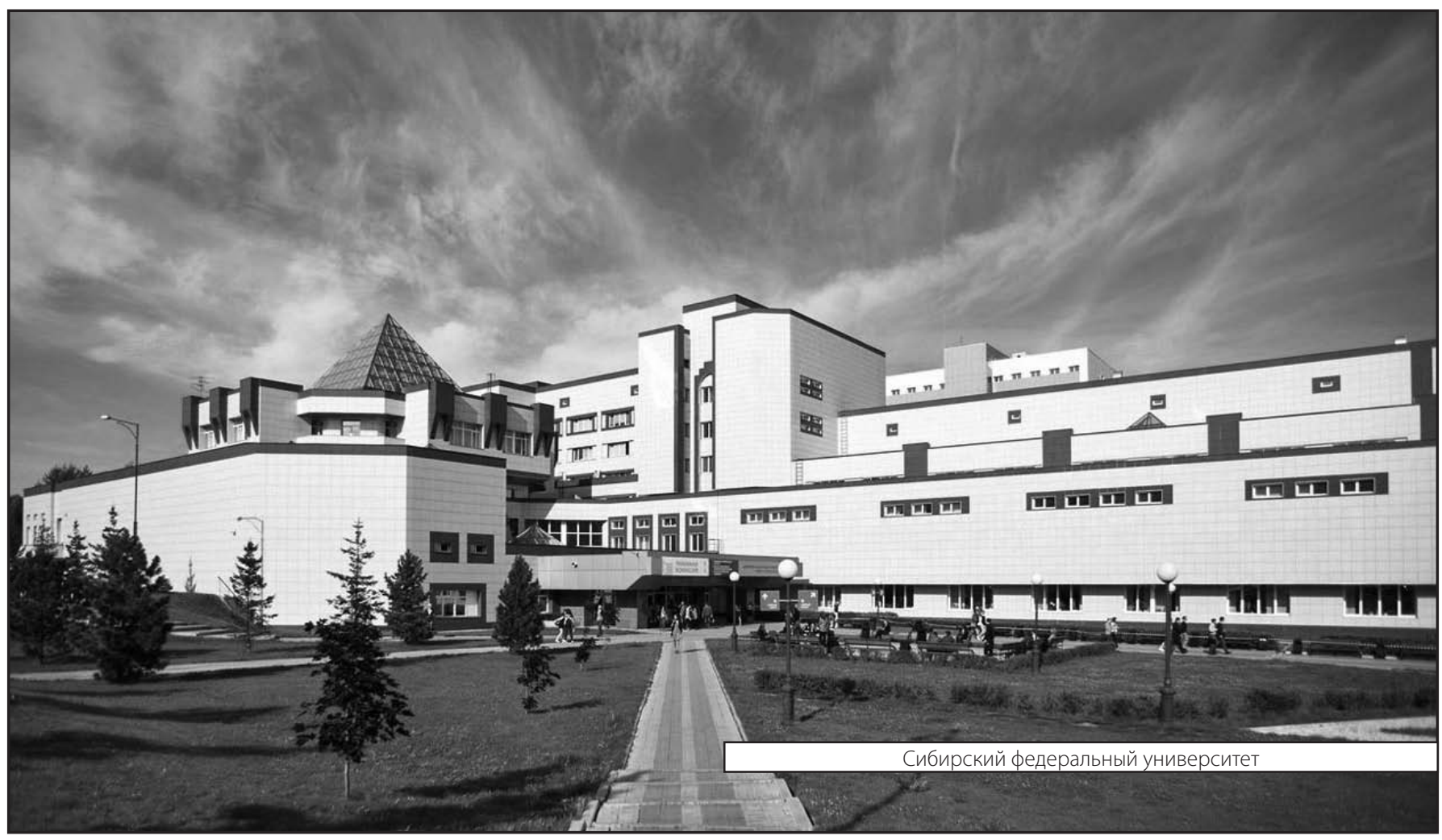

